\title{
Characterization of Maltese pottery of the Late Neolithic, Bronze Age and Punic Period by neutron activation analysis
}

\author{
H. MOMMSEN ${ }^{1}$, A. BONANNO ${ }^{2}$, K. CHETCUTI BONAVITA ${ }^{2}$, I. KAKOULLI ${ }^{3}$,

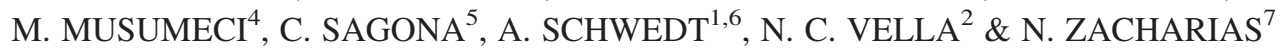 \\ ${ }^{1}$ Helmholtz-Institut für Strahlen- und Kernphysik, University of Bonn, \\ Nussallee 14-16, 53115 Bonn, Germany (e-mail: mommsen@hiskp.uni-bonn.de) \\ ${ }^{2}$ Department of Classics and Archaeology, University of Malta, Tal-Qroqq MSD 06, Malta \\ ${ }^{3}$ The UCLA/Getty Archaeological and Ethnographic Conservation Program, A410 Fowler, \\ Los Angeles, CA 90095-1510, USA \\ ${ }^{4}$ Academic Division, MATSEC Support Unit, University of Malta, Tal-Qroqq, \\ Msida MSD 06, Malta \\ ${ }^{5}$ School of Fine Arts, Classical Studies and Archaeology, University of Melbourne, \\ Melbourne, Vic. 3010, Australia \\ ${ }^{6}$ Present address: Equip de Recerca Arqueomètrica de la Universitat de Barcelona, \\ Departament de Prehistòria, Història Antiga i Arqueologia, C/de Baldiri Reixac, \\ s/n, 08028 Barcelona, Spain \\ ${ }^{7}$ Laboratory of Archaeometry, Institute of Materials Science, NCSR Demokritos, \\ Aghia Paraskevi, 15310 Attiki, Greece
}

\begin{abstract}
A set of 41 samples from Tas-Silg, Malta, has been analysed by neutron activation. It contained nine ware groups formed by visual examination covering the Late Neolithic, Bronze Age and Punic Periods (c. 3000-218 BC). Despite this diversity and long time range, seven of these ware groups, including the 'Thermi Ware', all have a similar chemical composition and, therefore, have been made from the same clay. This points most probably to a local origin. One group from the Punic Period, containing only Bricky Red cooking ware, is chemically separate and represents a second distinct pattern probably assignable to a local production. Five amphora sherds also from the Punic Period, and consisting of a micaceous fabric, all have different chemical characteristics and are probably imports from overseas production sites of unknown location.
\end{abstract}

Since 1996 the University of Malta, through the Department of Classics and Archaeology, has conducted archaeological excavations at the ancient sanctuary site at Tas-Silg, Malta. A substantial amount of ancient ceramics from stratified deposits has been recovered in the course of these excavations. From the outset, one of the principal aims of the project has been to identify ceramic ware types at the site, ranging from its prehistoric origins (c. $3000 \mathrm{BC}$ ) into the Punic Period, and beyond to more recent periods. In 2001, after five seasons of scientific excavations and rigorous extensive analysis, a point has been reached at which the range of wares at the site had been classified at the macroscopic level by visual inspection. Details about the site at Tas-Silg and its archaeological context are available in a preliminary report (Bonanno et al. 2000), where a detailed description of the various types of pottery, its fabrics, styles and decorations is given by C. Sagona.

The next stage in the pottery study was the chemical classification of the various types of wares using neutron activation analysis (NAA). As is well known, the minor and trace element concentrations in pottery reflect mainly the composition of the clay paste prepared by the potters, which depends mainly on the geochemical composition of the clay beds exploited (e.g. Perlman \& Asaro 1969; Jones 1986; Mommsen 2001). Therefore, the concentration patterns in pottery point to their production places, assuming that the raw clays available in the region have been used by the potters to prepare their pastes and 
that clays have not been traded. The aim of this study was to determine if the pottery ware types were produced from the same or different clay pastes and, if possible, if types of local production could be distinguished from imported types from foreign, overseas workshops. It was anticipated that this might give some insight into Malta's trade relations, especially during the Bronze Age and the Punic Period.

\section{Sample choice and description}

An initial set of 40 pottery sherds has been selected for chemical analysis by NAA. Having identified visually and haptically a number of ware types, C. Sagona, responsible for the TasSilg typology, proceeded to select eight of the most common or characteristically distinct ware type groups excavated at Tas-Silg for further comparative analyses. Five sherds of vessels of different shapes from each ware type were selected as being representative of that ware type and examined with the aid of a magnifying glass. Details of the fabric, shape, inclusions, surface treatment and colour were noted for each sherd. In addition, one sherd of a 'Thermi Ware' bowl as a ninth ware type excavated at Tas-Silg was available for NAA (Sagona in Bonanno et al. 2000, p. 87, fig. 9.4). This ware is assigned to the Early Bronze Age of the Aegean. Identified as 'Thermi Ware' are bowls and pedestal bowls with an internally thickened lip decorated with dot-filled incised triangles, for which a close parallel was identified in Early Bronze Age Thermi (Lesbos). Traditionally thought to be imported from the east, it occurs also in Castelluccio levels in eastern Sicily. Matters are further complicated by the fact that some sherds were discovered in Temple Period contexts.

An overview of the sample set is given in Table 1. Although all the ware type groups classified by visual examination are distinct from other ware types, there are notable differences between sherds within any one group, such as extent and nature of inclusions, i.e. vessels of the same ware type were produced from clays with different non-plastic admixtures. This is particularly the case for the Temple Period Wares, Borg in-Nadur Wares, and micaceous Wares. But because such inclusions are usually poorer in trace elements compared with the higher concentrations in clays, NAA could reveal if the same clay bed was exploited for the preparation of these different pastes.

The nine ware types selected are attributed to five time periods. The Late Neolithic Temple Period is represented by sherds Silg 16-20, the
Early Bronze Age Period by the 'Thermi Ware' sherd Silg 43, and the Late Bronze Age Borg in-Nadur phase by sherds Silg 1-5. One sample, Silg 42, is from an early modern tile and was included as a possible reference piece. The remaining 30 sherds all belong to the Punic Period and comprise the following ware types: Crisp Ware (Silg 6-10), Soft Brown Ware (Silg 11-15), Biscuit Ware (Silg 21-25), Bricky Red Ware (Silg 31-35), Drab Coarse Ware (Silg 36-40), and Micaceous Wares (Silg 26-30), which have been described by Sagona in Bonanno et al. (2000). Although clay deposits with a rare scattering of biotite (brown mica) are found on the island (M. Pedley, pers. comm.; Digeronimo et al. 1981), the five amphora sherds (Silg 26-30) have muscovite (transparent mica) inclusions, each one having a characteristically distinct fabric. This, together with the fact that only a small number of Micaceous sherds excavated at Tas-Silg can be identified, suggests that they are imports.

\section{Analytical procedure and data evaluation}

Neutron activation analysis (NAA) is a method very well suited to classify pottery by chemical means, as it is multi-elemental, sensitive down to the trace element level, and precise (e.g. Perlman \& Asaro 1969; Mommsen 2004). At the Helmholtz-Institut für Strahlen- und Kernphysik, University of Bonn, only $80 \mathrm{mg}$ of pottery powder are needed for an analysis. The sample is taken by drilling with a pointed sapphire-drill of $10 \mathrm{~mm}$ diameter, usually on the internal surface of the sherds, leaving only a shallow depression. The neutron irradiations are carried out at the research reactor in Geesthacht. The analytical procedure has been described by Mommsen et al. (1991). It is a modified version of that given by the former Berkeley group (Perlman \& Asaro 1969). As the Bonn pottery standard is calibrated against the Berkeley standard, our concentration data can be compared directly with the values of this group. A calibration to other standards in use has been given by Hein et al. (2002).

The comparison of the measured elemental data and the formation of groups of samples having a similar composition are done by a multivariate statistical filtering procedure developed in Bonn (Beier \& Mommsen 1994a,b) using a Mahalanobis distance search (Harbottle 1976). In contrast to the common statistical methods such as cluster analysis or principal component analysis, it is able to take into consideration two important features: (1) individual experimental errors; (2) a possible constant 
Table 1. List of sherds from Tas-Silg, Malta, studied by NAA

\begin{tabular}{|c|c|c|c|}
\hline $\begin{array}{l}\text { Sample } \\
\text { number }\end{array}$ & $\begin{array}{l}\text { Excavation } \\
\text { inventory number }\end{array}$ & $\begin{array}{l}\text { Ware type name, } \\
\text { time period }\end{array}$ & $\begin{array}{l}\text { Fabric description: } \\
\text { fabric texture/surface } \\
\text { treatment/inclusions }\end{array}$ \\
\hline Silg 1 & TSG96/2112/5 & Borg in-Nadur Ware, Bronze Age & Coarse/burnish/quartzite grit \\
\hline Silg 2 & TSG96/2112/15 & Borg in-Nadur Ware, Bronze Age & Coarse/burnish/sparse grog \\
\hline Silg 3 & TSG96/2097/6 & Borg in-Nadur Ware, Bronze Age & Fine/burnish/moderate grog \\
\hline Silg 4 & TSG96/2101/5 & Borg in-Nadur Ware, Bronze Age & Coarse/quartzite grit \\
\hline Silg 5 & TSG96/205/47 & Borg in-Nadur Ware, Bronze Age & Fine/burnish/moderate grog \\
\hline Silg 6 & TSG96/2019/28 & Crisp Ware, Punic Period & Fine/slip/moderate grog \\
\hline Silg 7 & TSG96/2061/24 & Crisp Ware, Punic Period & Fine/slip/moderate grog \\
\hline Silg 8 & TSG96/1010/14 & Crisp Ware, Punic Period & Coarse/slip/grog \\
\hline Silg 9 & TSG96/2097/17a & Crisp Ware, Punic Period & Fine/slip \\
\hline Silg 10 & TSG96/29/32 & Crisp Ware, Punic Period & Fine/thick slip/brown rock? grit \\
\hline Silg 11 & TSG96/2054/15 & Soft Brown Ware, Punic Period & Fine/self-slip/grog specks \\
\hline Silg 12 & TSG96/210/4 & Soft Brown Ware, Punic Period & Fine/self-slip/Ca specks \\
\hline Silg 13 & TSG96/23/8 & Soft Brown Ware, Punic Period & Refined/self-slip \\
\hline Silg 14 & TSG96/2077/14 & Soft Brown Ware, Punic Period & Coarse/self-slip/grog, Ca grit \\
\hline Silg 15 & TSG96/2092/33 & Soft Brown Ware, Punic Period & Fine/slip/grog specks \\
\hline Silg 16 & TSG96/9/1 & Temple Period Ware, Late Neolithic & Coarse drab/slip/moderate grog \\
\hline Silg 17 & TSG96/11/63 & Temple Period Ware, Late Neolithic & Fine/burnish/red specks \\
\hline Silg 18 & TSG96/11/57 & Temple Period Ware, Late Neolithic & Refined/burnish \\
\hline Silg 19 & TSG96/210/9 & Temple Period Ware, Late Neolithic & Refined/burnish/Ca specks \\
\hline Silg 20 & TSG96/220/27 & Temple Period Ware, Late Neolithic & Refined/burnish/Ca specks \\
\hline Silg 21 & TSG96/34/26 & Biscuit Ware, Punic Period & Coarse/slip/Ca grit \\
\hline Silg 22 & TSG96/205/19 & Biscuit Ware, Punic Period & Fine/slip/Ca grit \\
\hline Silg 23 & TSG96/205/49 & Biscuit Ware, Punic Period & Fine/slip/Ca specks \\
\hline Silg 24 & TSG96/105/9 & Biscuit Ware, Punic Period & Fine/slip/Ca specks \\
\hline Silg 25 & TSG96/2016/54 & Biscuit Ware, Punic Period & Coarse/slip/Ca grit \\
\hline Silg 26 & TSG96/205/54 & Micaceous Ware, Punic Period & Refined/muscovite mica \\
\hline Silg 27 & TSG96/204/28 & Micaceous Ware, Punic Period & Refined/slip/muscovite mica \\
\hline Silg 28 & TSG96/220/29 & Micaceous Ware, Punic Period & $\begin{array}{l}\text { Refined/mica-dusted/muscovite } \\
\text { mica }\end{array}$ \\
\hline Silg 29 & TSG96/220/23 & Micaceous Ware, Punic Period & Refined/self-slip/muscovite mica \\
\hline Silg 30 & TSG96/34/42 & Micaceous Ware, Punic Period & Refined/slip/muscovite mica \\
\hline Silg 31 & TSG96/34/36 & Bricky Red Ware, Punic Period & Coarse/cream slip/Ca grit \\
\hline Silg 32 & TSG96/34/33 & Bricky Red Ware, Punic Period & Coarse/self-slip/Ca grit \\
\hline Silg 33 & TSG96/34/37 & Bricky Red Ware, Punic Period & Coarse/self-slip/Ca grit \\
\hline Silg 34 & TSG96/2026/22 & Bricky Red Ware, Punic Period & Fine/self-slip/sparse Ca grit \\
\hline Silg 35 & TSG96/34/34 & Bricky Red Ware, Punic Period & Coarse/self-slip/Ca grit \\
\hline Silg 36 & TSG96/1033/1790 & Drab Coarse Ware, Punic Period & Coarse/slip/frequent grog \\
\hline Silg 37 & TSG96/1033/1375 & Drab Coarse Ware, Punic Period & Very coarse/slip/frequent grog \\
\hline Silg 38 & TSG96/1033/800 & Drab Coarse Ware, Punic Period & Coarse/slip/frequent grog \\
\hline Silg 39 & TSG96/1033/1229 & Drab Coarse Ware, Punic Period & Very coarse/slip/frequent grog \\
\hline Silg 40 & TSG96/1033/1291 & Drab Coarse Ware, Punic Period & Coarse/slip/moderate grog \\
\hline Silg 42 & - & Tile of structure, Early Modern & \\
\hline Silg 43 & TSG96/2061/9 & Thermi Ware, Early Bronze Age & $\begin{array}{l}\text { Thickened lip with dotted } \\
\text { decoration }\end{array}$ \\
\hline
\end{tabular}

shift of the data caused by diluting compounds in the samples. Examples of this evaluation procedure have been presented by Mommsen (2001) and Akurgal et al. (2002). The neglect of experimental errors during the groupforming procedure is dangerous in the case of elements measurable only with a large margin of error and might lead to wrong classifications. With regard to NAA as performed at Bonn, this mainly concerns the elements $\mathrm{Ca}, \mathrm{Ti}$ and $\mathrm{Ni}$.
For these elements, only isotopes excited by fast neutrons have long enough half lives to be measurable 5 days after the irradiations as done in Bonn. As a result of a substantial reduction of the fast neutron fraction in the irradiating neutron beam since an upgrading of the reactor in Geesthacht in the year 2000, these elements are currently determined only with large errors. However, consideration of errors allows their inclusion during grouping. In addition, possible 
constant shifts of all concentration values should be corrected during group formation to reduce the spreads of the average concentration values of the pottery groups obtained. Levigating the raw clays or adding tempering material such as sand or calcite in varying amounts will enrich or dilute the clay fraction of the paste, often changing all the concentration values by a constant factor. Besides such pottery-making practices, experimental errors, e.g. weighing errors and/or neutron flux heterogeneities, may also be the cause of such constant shifts. Therefore, constant shifts should be corrected by either using concentration ratios (Buxeda i Garrigos 1999) in statistical cluster analyses or, to be independent of the single concentration value chosen as denominator, performing a best relative fit of the individual datasets to the group mean values (Harbottle 1976). The reduction of the spreads of the elemental patterns observed in all our studies considering dilutions demonstrates that it is mainly the clay part of the paste that determines the provenance. The element concentrations of $\mathrm{As}, \mathrm{Ba}, \mathrm{Ca}$ and $\mathrm{Na}$ are found to scatter strongly in pottery groups made at the same workshop (see Table 1) and should be considered with care during the group-forming procedure (Mommsen 2004). In particular, As and $\mathrm{Na}$ are not and should not be included in the filtering procedure, as they are measured with small errors (see Table 4). Therefore, they will strongly influence the value of the calculated dilution factor and may result in an inappropriate factor.

\section{Results and discussion}

Some of the results of this study were rather unexpected. The evaluation of the NAA data revealed that most sherds of the set of samples from Tas-Silg have a well-defined and similar chemical composition, forming a group here named SILA. Its average concentrations $M$ and spreads $\sigma$ (root mean square deviations) are listed in Table 2. For many elements $(\mathrm{Ce}, \mathrm{Eu}$, $\mathrm{Fe}, \mathrm{La}, \mathrm{Sc}, \mathrm{Th}, \mathrm{Yb})$ spread values $<5 \%$ are found; nine more elements $(\mathrm{Co}, \mathrm{Cr}, \mathrm{Hf}, \mathrm{Lu}, \mathrm{Nd}$, $\mathrm{Rb}, \mathrm{Sm}, \mathrm{Ta}, \mathrm{Tb})$ scatter by $<10 \%$ around their mean values $M$. This result was obtained by employing the method of a best relative fit of the concentrations of each sample to the group mean values with the fit factors given in Table 3. Very high factors are found for the two Bronze Age samples Silg 1 and 4 (1.55 and 1.68 , respectively), i.e. the concentrations of these samples have to be increased by $55 \%$ and $68 \%$, respectively, to match the mean group pattern. A cross-section of one of the two sherds, sampled as Silg 1, is shown in Figure 1 (top). Silg 1 and 4 both have a high Ca content (18.7\% and $19.9 \%$, respectively), which points to $\mathrm{Ca}$ as at least one of the diluents. By visual examination, both samples were noted for their moderate amount of coarse quartzite inclusions; this also may account for their strong dilution. On the other hand, the concentrations for three of the oldest samples from the Temple Period (Silg 18-20) have to be lowered by more than $20 \%$ to match the group mean values; these samples have the highest concentrations of trace and minor elements in the whole group of samples. The cross-section of sherd sampled as Silg 18 is also shown in Figure 1 (bottom) for comparison. All three samples belong to thinwalled vessels having a fine-textured fabric, in contrast to sample Silg 16, which is a typical example of the Temple Period coarse ware with the usual concentrations of group SILA (fit factor $=0.99)$. Therefore, it may be concluded that samples Silg 18-20 are made from a refined clay paste compared with sample Silg 16 , where some non-plastic parts with low element concentrations have been taken out, giving no contribution to the measurable NAA data obtained at Bonn. Despite this unusually large range of fit or dilution factors, all members of the group SILA can be assumed to have been made from clay of the same geological formation, which was refined by different 'recipes', resulting in different absolute compositions. Their common origin is confirmed by the dilution-corrected NAA compositional data. Unexpectedly, also the 'Thermi Ware' sample Silg 43 , diluted by $16 \%$, belongs to group SILA. The fact that all these different wares are members of group SILA would not have been obtainable using standard statistical cluster analysis without corrections for possible inclusions.

As group SILA contains vessels of different time periods (Temple Period, Bronze Age, Punic Period) and of different archaeological types and shapes, the probability that this group represents the local workshop(s) in the region of Tas-Silg is very high. Therefore, the pattern SILA can be taken as a reference pattern for a pottery production centre possibly in the area of Tas-Silg, Malta. The possibility that all these different ware types during this long time period were imported from the same workshop somewhere overseas is extremely remote, but cannot be totally excluded, especially as, on the basis of plate tectonics, the southern part of Sicily and Malta belonged to the same Pelagian sea basin during the Miocene. More light will be shed on this issue only once reference material from the Sicilian coast facing Malta has been analysed. 
Table 2. Element concentrations of groups SILA (most probably Malta), SILB (probably Malta) and Seg2 (Segesta, Sicily)

\begin{tabular}{|c|c|c|c|c|c|c|}
\hline \multirow[b]{2}{*}{ As } & \multicolumn{2}{|c|}{$\begin{array}{c}\text { SILA } \\
27 \text { samples } \\
\mathrm{M} \pm \sigma(\%)\end{array}$} & \multicolumn{2}{|c|}{$\begin{array}{c}\text { SILB } \\
5 \text { samples } \\
\mathrm{M} \pm \sigma(\%)\end{array}$} & \multicolumn{2}{|c|}{$\begin{array}{c}\text { Seg2 } \\
5 \text { samples fit } \\
\text { factor } 0.93 \\
M \pm \sigma(\%)\end{array}$} \\
\hline & 7.50 & 15 & 11.2 & 9.9 & 4.33 & 42 \\
\hline $\mathrm{Ba}$ & 250 & 20 & 389 & 7.1 & 228 & 44 \\
\hline $\mathrm{Ca} \%$ & 10.2 & 23 & 3.49 & 6.0 & 7.33 & 16 \\
\hline $\mathrm{Ce}$ & 89.9 & 2.4 & 112 & 1.0 & 89.8 & 2.1 \\
\hline $\mathrm{Co}$ & 13.7 & 8.9 & 17.5 & 2.3 & 15.1 & 9.7 \\
\hline $\mathrm{Cr}$ & 111 & 7.4 & 110 & 2.2 & 117 & 4.1 \\
\hline Cs & 5.98 & 13 & 6.24 & 7.6 & 7.42 & 4.0 \\
\hline $\mathrm{Eu}$ & 1.44 & 3.2 & 2.03 & 2.3 & 1.40 & 1.6 \\
\hline $\mathrm{Fe} \%$ & 4.34 & 4.6 & 5.11 & 1.7 & 4.65 & 2.2 \\
\hline $\mathrm{Ga}$ & 25.6 & 15 & 27.3 & 10 & 27.1 & 8.8 \\
\hline Hf & 4.59 & 6.7 & 9.45 & 4.5 & 5.07 & 13 \\
\hline $\mathrm{K} \%$ & 2.44 & 13 & 2.48 & 5.9 & 2.30 & 8.2 \\
\hline $\mathrm{La}$ & 42.0 & 4.4 & 54.2 & 1.3 & 43.3 & 2.7 \\
\hline $\mathrm{Lu}$ & 0.38 & 5.3 & 0.60 & 2.9 & 0.41 & 6.2 \\
\hline $\mathrm{Na} \%$ & 0.56 & 40 & 0.97 & 5.3 & 0.43 & 52 \\
\hline $\mathrm{Nd}$ & 30.5 & 6.4 & 43.8 & 4.0 & 29.2 & 11 \\
\hline $\mathrm{Ni}$ & 92.0 & 40 & 104 & 34 & 81.2 & 37 \\
\hline $\mathrm{Rb}$ & 108 & 6.9 & 124 & 6.7 & 124 & 3.2 \\
\hline $\mathrm{Sb}$ & 0.56 & 14 & 0.71 & 5.2 & 0.49 & 8.8 \\
\hline $\mathrm{Sc}$ & 15.4 & 3.0 & 17.6 & 0.5 & 16.8 & 1.4 \\
\hline $\mathrm{Sm}$ & 5.50 & 7.1 & 8.10 & 7.1 & 5.18 & 6.5 \\
\hline $\mathrm{Ta}$ & 1.21 & 6.1 & 1.93 & 2.1 & 1.26 & 3.1 \\
\hline $\mathrm{Tb}$ & 0.79 & 6.1 & 1.20 & 7.5 & 0.77 & 9.1 \\
\hline Th & 11.8 & 2.5 & 15.2 & 1.3 & 12.5 & 2.6 \\
\hline $\mathrm{Ti} \%$ & 0.55 & 17 & 0.63 & 12 & 0.43 & 14 \\
\hline $\mathrm{U}$ & 2.97 & 12 & 2.49 & 4.1 & 3.05 & 11 \\
\hline W & 1.75 & 13 & 2.42 & 16 & 2.17 & 12 \\
\hline $\mathrm{Yb}$ & 2.63 & 3.5 & 4.28 & 2.0 & 2.79 & 2.7 \\
\hline $\mathrm{Zn}$ & 125 & 15 & 100 & 4.8 & 118 & 8.0 \\
\hline $\mathrm{Zr}$ & 106 & 25 & 286 & 9.9 & 243 & 13 \\
\hline
\end{tabular}

Average concentration values $\mathrm{M}$ in $\mu \mathrm{g} \mathrm{g}^{-1}$ ( $\mathrm{ppm}$ ), if not indicated otherwise, and spreads $\sigma$ in $\%$ of M; group Seg2 corrected for dilution with respect to SILA.

When the databank of patterns in Bonn is searched for groups of similar compositions, the closest group to SILA is a group from Segesta, Sicily. This is mentioned here to stress again the importance of high precision. Five sherds, all kiln wasters of amphorae and common wares from a Hellenistic-Roman kiln site at Segesta and, therefore, made there locally with a high probability, form this group, named Seg2 (Montana et al. 2003). If the values of group Seg2 are adjusted by a fit factor of 0.93 , group SILA is very close to

Table 3. List of group members and their individual fit factors (in parentheses) to the mean group values calculated by using all elements given in Table 2 except As, Ba, Ca and Na (see text)

\begin{tabular}{|c|c|c|c|c|c|c|c|c|c|c|}
\hline \multicolumn{11}{|c|}{ Group SILA, 27 samples } \\
\hline \multirow[t]{3}{*}{ Silg } & $1(1.55)$ & $3(1.07)$ & \multicolumn{2}{|c|}{$4(1.68)$} & $5(0.93)$ & $6(0.95)$ & $7(0.95)$ & $8(0.86)$ & $9(0.95)$ & $11(1.21)$ \\
\hline & $12(1.06)$ & $13(1.03)$ & \multicolumn{2}{|c|}{$14(1.14)$} & 15 (1.13) & $16(0.99)$ & $18(0.71)$ & $19(0.79)$ & $20(0.72)$ & $21(1.08)$ \\
\hline & $22(0.89)$ & $23(0.96)$ & \multicolumn{2}{|c|}{$24(0.84)$} & $25(0.88)$ & $37(1.05)$ & $38(1.02)$ & $39(1.03)$ & $40(1.06)$ & $43(1.16)$ \\
\hline \multicolumn{11}{|c|}{ Group SILB, 5 samples } \\
\hline Silg & $31(0.98)$ & $32(1.00)$ & \multicolumn{2}{|c|}{$33(0.98)$} & $34(1.03)$ & $35(1.00)$ & & & & \\
\hline \multicolumn{11}{|c|}{ Chemical singles, 10 samples } \\
\hline Silg & 2 & 10 & 17 & 26 & 27 & 28 & 29 & 30 & 36 & 42 \\
\hline
\end{tabular}



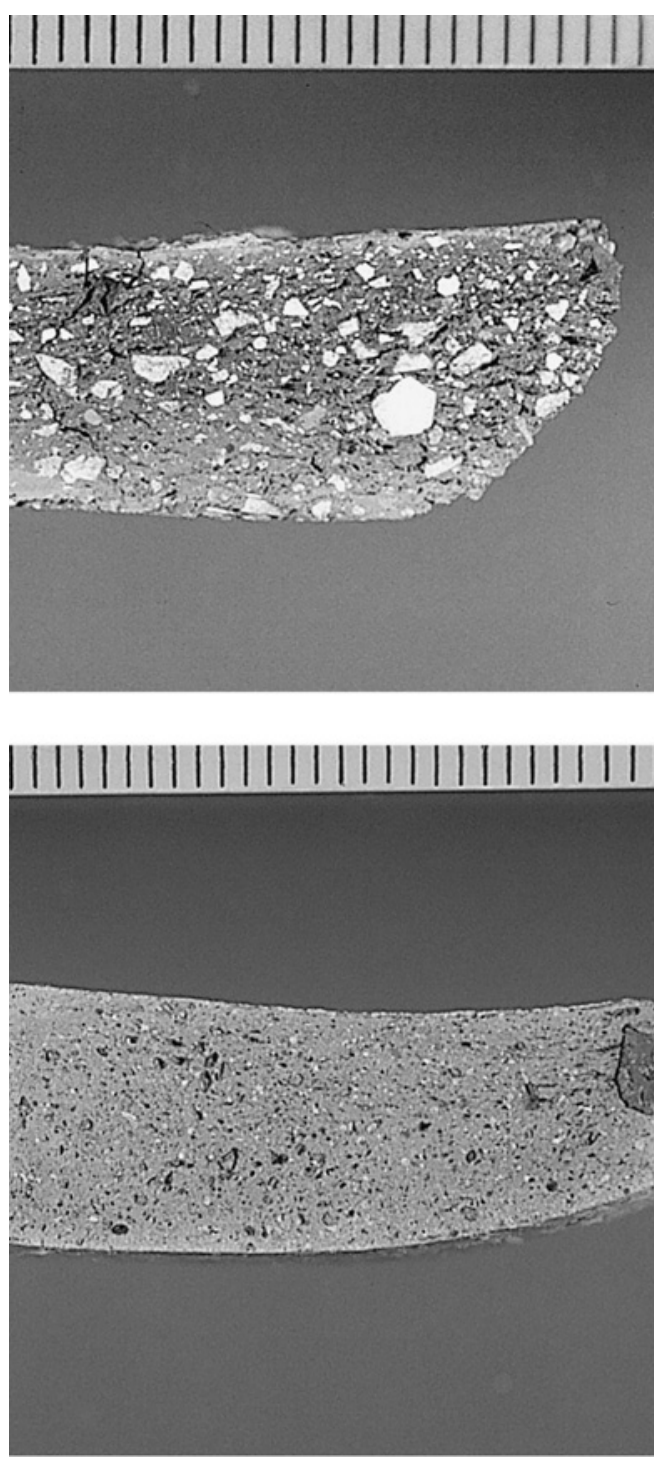

Fig. 1. Cross-sections of the coarse Borg in-Nadur sherd (sample Silg 1, above) and of the fine-textured sherd of the Temple Period (sample Silg 18, below). Both are made from the clay with pattern SILA. The concentrations of sample Silg 1 and Silg 18 have to be corrected by a fit factor of 1.55 and of 0.71 , respectively, to match pattern SILA.

group Seg2, as can be seen from Table 2 . Figure 2 shows a graphical comparison between groups SILA and Seg2 made by plotting the concentration differences for all 30 elements in units of the average spread values $\sigma_{\text {ave }}$ as a bar diagram. The only clearly differing element is $\mathrm{Zr}$, which is difficult to measure at Bonn, but because three elements measured with high precision, $\mathrm{Cs}$, $\mathrm{Rb}$ and $\mathrm{Sc}$, differ by slightly more than $2 \sigma_{\mathrm{ave}}$, the two patterns can be chemically separated. Without this high precision of the chemical patterns, which is obtained here only by the correction of the unusually large dilution effects, the groups of Tas-Silg, Malta, and Segesta, Sicily, could not have been distinguished. The local wasters from Segesta are obviously made using a clay formation that can be distinguished from the clay of group SILA only by using appropriate evaluation procedures on the data.

A second chemical group SILB is formed by five sherds of the type Bricky Red Cooking Ware, dated to the Punic Period. The mean values and spreads are also listed in Table 2. This group has a very different chemical composition from group SILA with on average $21 \%$ higher concentrations in nearly all elements except for $\mathrm{Ca}, \mathrm{Cr}, \mathrm{U}$ and $\mathrm{Zn}$. This may be due to the fact that the local potters, in considering the special requirements for cooking ware, have produced a different paste deliberately by using different clays or clay mixtures for the production of these wares (see Kilikoglou et al. 1998). In this case, pattern SILB may form a second local pattern for the site at Tas-Silg. This assumption is strengthened by the comparatively large presence of this ware and by its typological similarity to the local Biscuit Ware of group SILA (Bonanno et al. 2000). However, as only five pieces with pattern SILB were identified, the assumption of a local production is not very conclusive; all five vessels of this group might have been imported from a production site with this as yet unknown pattern. On the other hand, several sherds of this ware type carry inscriptions to Ashtart, which were inscribed before firing. It is most unlikely that this was done abroad for Maltese consumption. No other pattern in our databank in Bonn is close to SILB.

During a chemical classification of pottery several chemically single samples are usually found. One cannot conclude much about these outliers. A chemically single sample might have been contaminated in the laboratory, during burial or already in the production workshop, or it might represent the first member of a still unknown production series with a different paste. The individual NAA data for all singles found in this study are listed in Table 4. In the set of non-micaceous wares from Tas-Silg five such singles (Silg 2, 10, 17, 36, 42) were identified. Silg 42 is the Early Modern tile. Its composition does not help to localize any of the patterns found at Tas-Silg. By visual inspection Silg 17 has been noted as having a unique fabric 


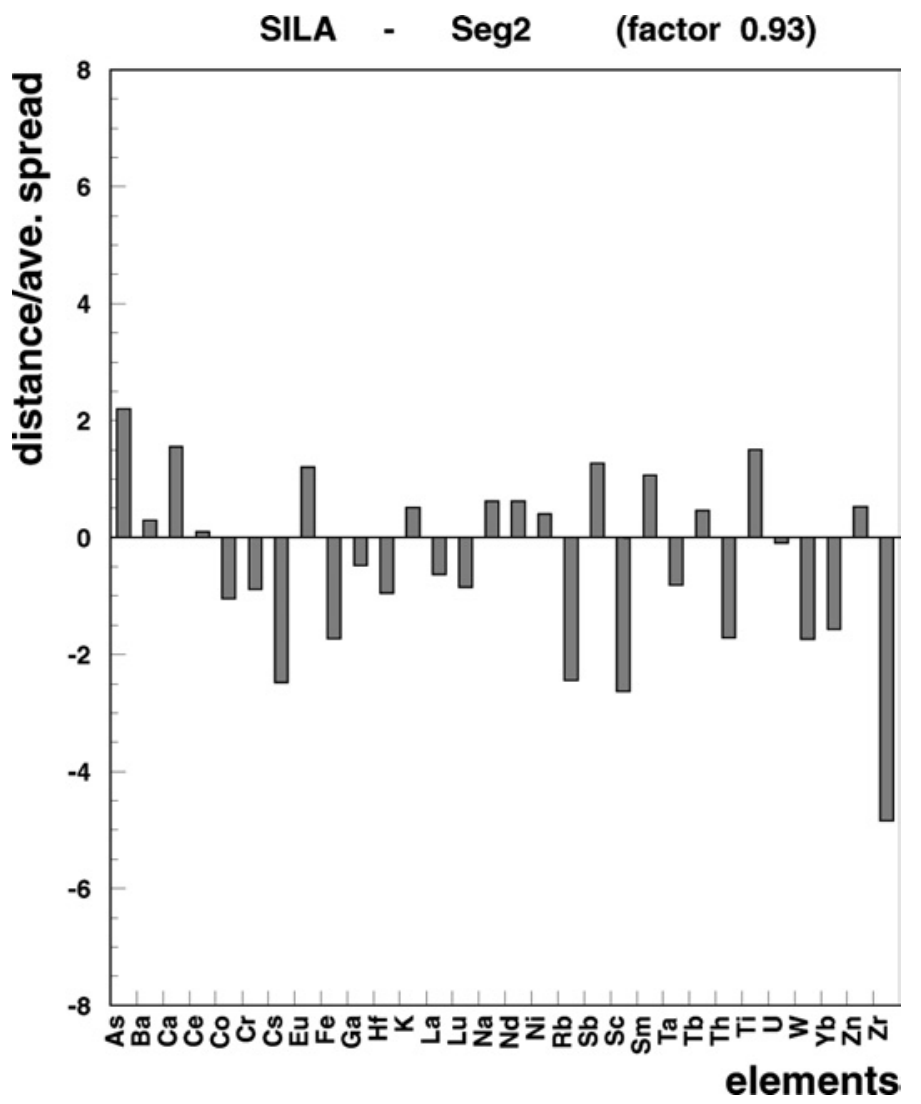

Fig. 2. Normalized differences (in units of average spread value) of average concentrations of the 30 elements given in Table 2 of the pottery groups SILA (27 samples) and Seg2 (5 samples). The concentrations of group Seg2 are multiplied by a fit factor of 0.93 to obtain an optimal agreement.

differing from that of the other Temple Period sherds. As such, it has been given the name Sandy Pink Ware because of its fine-textured red clay with small red inclusions. Its wellburnished exterior surface, however, is typical of the Temple Period. This may point towards a different production group. With regard to Silg 10, whereas Crisp Ware fabrics are known to have a number of inclusions such as calcium grit or grog, Silg 10 is unusual for its matt brown, coarse inclusions, which may account for its unique chemical characteristics. Finally, the whole group of Micaceous amphorae of the Punic Period (Silg 26-30), believed to be imported to Malta, consists of chemical singles; they all have different compositions. The element analysis permits the conclusion that all five pieces were produced with different pastes, presumably in different workshops. These amphorae seem to have been used as transport containers, which would explain the presence of vessels from different production sites in this group. As the five patterns of the amphorae are unknown to us, we are not able to assign them to production workshops. More work on vessels from different overseas sites is necessary to locate the origin of these chemical outliers.

\section{Conclusion}

NAA of 41 sherds excavated at Tas-Silg consisting of nine ware types was able to show the unexpected result that only one characteristic clay with a well-defined, sharp concentration pattern of many elements, SILA, was used for seven of these ware types, including the 'Thermi Ware'. The dating of these ware types defines the time range of the use of this clay as beginning with the Late Neolithic Temple Period (about 3000 $\mathrm{BC}$ ) and lasting through the Bronze Age (Tarxien Cemetery and Borg in-Nadur phases, $2500-700$ BC) until the Punic Period (550-218 


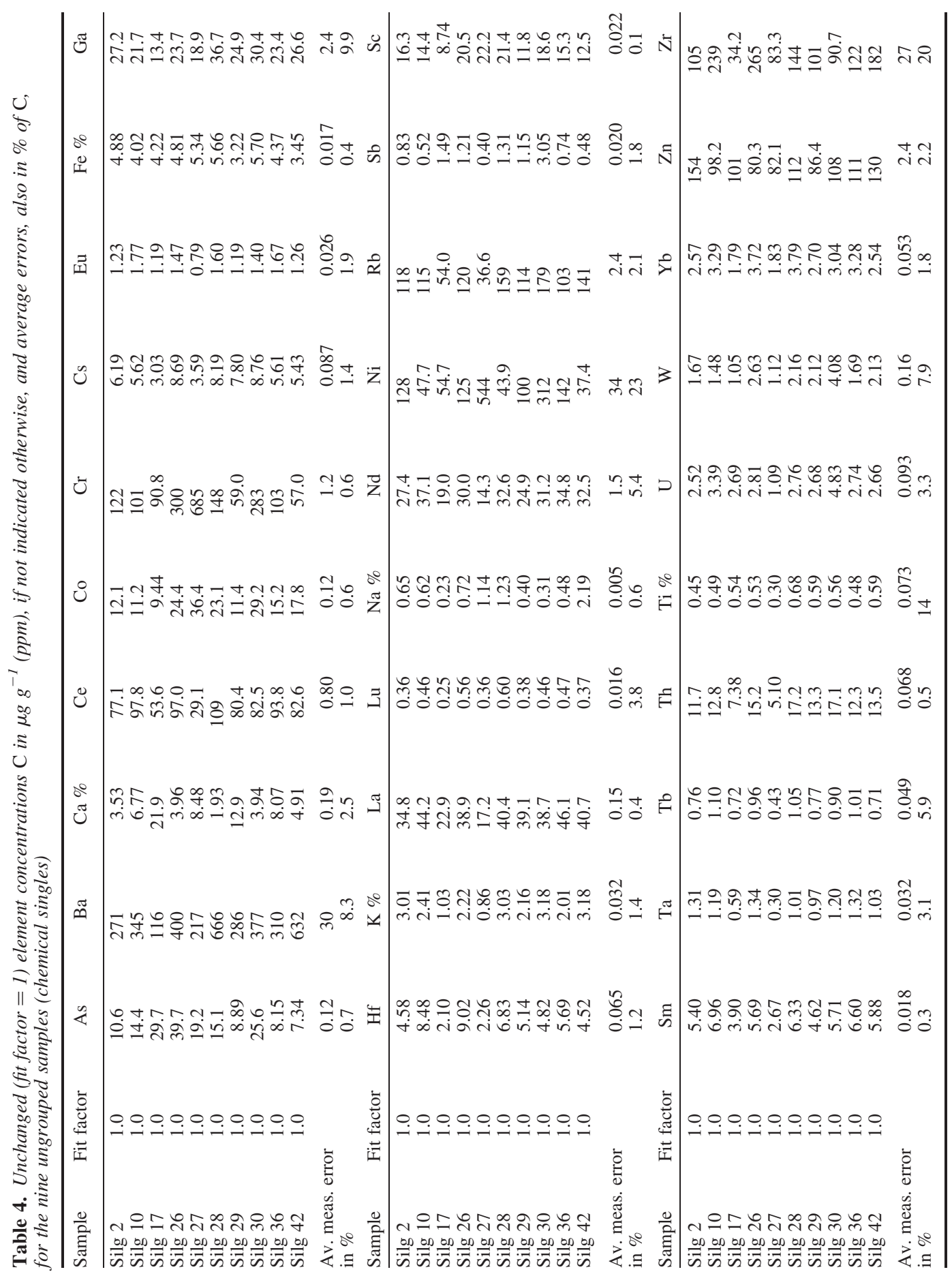


BC). This large time span together with the presence of different ware types in the group argues for a local production of all these pottery vessels, although, because of the lack of reference material, no definite proof is obtained. A second paste with pattern SILB was in use during the Punic Period for the Bricky Red cooking ware and was probably also locally produced. In contrast, the group of five Micaceous amphorae found in Tas-Silg all have different chemical patterns and are most probably imports from five different workshops outside Malta.

We would like to thank the staff of the research reactor at Geesthacht, Germany, for the neutron irradiations, and Y. Taniguchi (formerly of the Malta Centre for Restoration) and M. H. Pedley (University of Hull, UK) for their advice and comments.

\section{References}

Akurgal, M., Kerschner, M., Mommsen, H. \& NiemeIER, W.-D. 2002. Töpferzentren der Ostägäis, Archäometrische und archäologische Untersuchungen zur mykenischen, geometrischen und archaischen Keramik aus Fundorten in Westkleinasien (mit einem Beitrag von S. Ladstätter). 3. Ergänzungsheft der Jahreshefte des Österreichischen Archäologischen Institutes, Wien

Beier, Th. \& Mommsen, H. 1994a. Modified Mahalanobis Filters for grouping pottery by chemical composition. Archaeometry, 36, 287-306.

Beier, Th. \& Mommsen, H. 1994b. A method for classifying multidimensional data with respect to uncertainties of measurement and its application to archaeometry. Naturwissenschaften 91, 546-548.

Bonanno, A., Frendo, A. J. \& Vella, N. C. (eds) 2000. Excavations at Tas-Silg, Malta: a preliminary report on the 1996-1998 campaigns conducted by the Department of Classics and Archaeology of the University of Malta. Mediterranean Archaeology, 13, 67-114
BuXEDA I GARRIGOS, J. 1999. Alteration and contamination of archaeological ceramics: the perturbation problem. Journal of Archaeological Science, 26, 295-313.

Digeronimo, I., Grasso, M. \& Pedley, H. M. 1981. Palaeoenvironment and palaeogeography of Miocene marls from southeast Sicily and the Maltese Islands. Palaeogeography, Palaeoclimatology, Palaeoecology, 34, 173-189.

Harbottle, G. 1976. Activation analysis in archaeology. In: Newton, G. W. A. (ed.) Radiochemistry 3. Chemical Society, London, 33-72.

Hein, A., Tsolakidou, A., Iliopoulos, I., Mommsen, H., Buxeda i Garrigos, J., Montana, G. \& Kilikoglou, V. 2002. Standardisation of elemental analytical techniques applied to provenance studies of archaeological ceramics-an interlaboratory calibration study. Analyst, 127, 542-553.

Jones, R. E. 1986. Greek and Cypriot Pottery. British School at Athens, Fitch Occasional Papers, 1.

Kilikoglou, V., Vekinis, G., Maniatis, Y. \& Day, P. M. 1998. Mechanical performance of quartztempered ceramics: Part I, Strength and toughness. Archaeometry, 40, 261-280.

Mommsen, H. 2001. Provenance determination of pottery by trace element analysis: problems, solutions and applications. Journal of Radioanalytical and Nuclear Chemistry, 247, 657-662.

Mommsen, H. 2004. Short note: provenancing of pottery-the need for an integrated approach? Archaeometry, 46, 267-271.

Mommsen, H., Kreuser, A., Lewandowski, E. \& Weber, J. 1991. Provenancing of pottery: Status report and grouping. In: Hughes, M. Cowell, M. \& Hooк, D. (eds) Neutron Activation and Plasma Emission Spectrometric Analysis in Archaeology. British Museum Occasional Papers, 82, 57-65.

Montana, G., Mommsen, H., Iliopoulos, I., Schwedt, A. \& Denaro, M. 2003. Petrography and chemistry of thin-walled ware from a HellenisticRoman site at Segesta (Sicily). Archaeometry, 45, 375-389.

Perlman, I. \& Asaro, F. 1969. Pottery analysis by neutron activation. Archaeometry, 11, 21-52. 
